TI 2011-121/3

Tinbergen Institute Discussion Paper

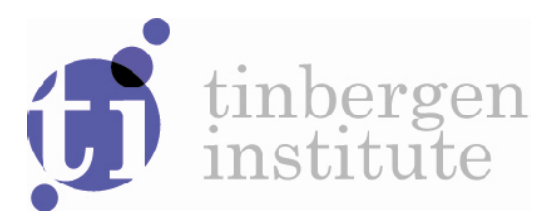

\title{
Estimating the Effects of Recent Disability Reforms in The Netherlands
}

Ian-Maarten van Sonsbeek

Raymond Gradus* 
Tinbergen Institute is the graduate school and research institute in economics of Erasmus University Rotterdam, the University of Amsterdam and VU University Amsterdam.

More TI discussion papers can be downloaded at http://www.tinbergen.nl

Tinbergen Institute has two locations:

Tinbergen Institute Amsterdam

Gustav Mahlerplein 117

1082 MS Amsterdam

The Netherlands

Tel.: +31(0)205251600

Tinbergen Institute Rotterdam

Burg. Oudlaan 50

3062 PA Rotterdam

The Netherlands

Tel.: +31(0)10 4088900

Fax: $+31(0) 104089031$

Duisenberg school of finance is a collaboration of the Dutch financial sector and universities, with the ambition to support innovative research and offer top quality academic education in core areas of finance.

DSF research papers can be downloaded at: http://www.dsf.nl/

Duisenberg school of finance

Gustav Mahlerplein 117

1082 MS Amsterdam

The Netherlands

Tel.: +31(0)20 5258579 


\title{
Estimating the effects of recent disability reforms in the Netherlands ${ }^{1}$
}

\author{
Jan-Maarten van Sonsbeek and Raymond Gradus \\ VU University Amsterdam, De Boelelaan 1105, 1081 HV Amsterdam \\ Corresponding E-mail: jvsonsbeek@minszw.nl
}

\begin{abstract}
In the 1980s and 1990s, disability benefit rates in the Netherlands were among the highest in the world. However, since the beginning of this century the number of disability cases has dropped remarkably due to some very successful policy reforms. An administrative dataset of Dutch disability benefit recipients from 1999 until 2010 has been used for analyzing the immediate effects on disability inflow and outflow of the recent policy measures.

Three measures introduced between 1998 and 2004 have had a large effect reducing the inflow into the disability scheme by over 40 percentage points. The new disability scheme introduced in 2006 adds another reduction of over 20 percentage points. Effects differ substantially over demographic groups and sectors of economic activities. Furthermore, it is shown that the effects of re-examinations of the disability stock are substantial in the short run but may be overcompensated in the long run by adverse effects.
\end{abstract}

JEL Classification: C15, H55, J26

Keywords: disability, policy reform

\footnotetext{
${ }^{1}$ The authors would like to thank seminar and conference participants at the Netherlands Bureau for Economic Policy Analysis (CPB), VU University Amsterdam and the 2010 conference of the International Institute of Public Finance, particularly our discussants Ed Westerhout and Kees Folmer at the latter occasion, who provided many comments that greatly helped to improve upon this paper.
} 


\section{Introduction}

In the 1980s and 1990s, disability benefit rates in the Netherlands were among the highest in the world. In 2002 the number of disability benefit recipients approached the political sensitive level of one million, 800,000 of which in the employees' scheme. When the inflow rates at that time would have been continued into the future, the number of disability benefit recipients would have risen to 1.2 million or $17 \%$ of the working population by 2040 in the employees' scheme (Van Sonsbeek, 2011). At the time of writing, nine years later, the Netherlands is considered one of the prime examples of effective policy reform in the disability scheme (Prinz and Tompson, 2009). The yearly inflow into the scheme has dropped to 40 percent the level that was common until 2001 and the long term estimate of the number of disability benefits in 2040 currently amounts to 370,000 (Van Sonsbeek and Gradus, 2010).

The Netherlands was not the only country with a disability problem (see e.g. Autor and Duggan, 2006). Consequently, the reforms in the Netherlands follow a broader international trend from disability schemes focusing on compensation of income loss towards schemes focusing on reintegration (OECD, 2003). Also in other countries such as Switzerland, Australia, the United Kingdom and Sweden, disability reforms took place (Prinz and Tompson, 2009, pp. 51-55). Switzerland undertook a series of reforms in recent years focussing on early identification and intervention in order to prevent long-term disability benefit dependency. In 2003, the Australian Disability support pension (DSP) was limited to people with a very restricted capacity to work in response to the rapid growth of the DSP program over the last three decades (Cai and Gregory, 2004). In addition, in 2006, the government introduced a comprehensive welfare-to-work approach. In the UK, the government has improved incentives to work through the Disabled Person's Tax Credit, which is based on the principle that work is generally good for people's health (Jones et al., 2006). In Sweden, the fiscal crunch in the beginning of the 1990's did make a disability reform possible at earlier years. However, whereas these earlier attempts were not successful, reforms since 2002 yielded impressive results (Prinz and Tompson, 2009).

Between 1998 and 2006 a series of reforms have taken place in the Netherlands. Although it is clear that the combined effect of these reforms is very substantial, there has not been any conclusive research investigating the separated and combined effects of the reforms simultaneously up till now. This paper tries to fill this gap using administrative datasets of all disability benefit recipients in the Netherlands from 1999 until 2010. The immediate effects of 
inflow- and outflow-related policy measures on disability inflow and outflow are assessed, controlling for business cycle and seasonal effects. The effects of the different measures are quantified both in a general model and in age/gender- and sector-specific models since the measures may affect different demographic groups and sectors.

The structure of this paper is as follows. In section 2 an overview of the Dutch disability system and a history of the most important past policy measures are given. In section 3 , the development of the inflow- and outflow rates are modelled in order to disentangle the individual effects of the various policy reforms using the macro regression approach. Section 4 gives the estimation results and section 5 concludes with some policy recommendations and topics for further research.

\section{The Dutch disability insurance schemes}

In this section, an overview is given of the Dutch disability insurance schemes and the major reforms that have taken place since their introduction. As the observation period of the data used in this paper runs from 1999 to 2010, the reforms are split into two parts. Section 2.1 focuses on the policy measures taken before the end of the 1990s. Section 2.2 focuses on the more recent policy measures, starting with the introduction of premium differentiation for employers in 1998. Section 2.3 presents an overview of the literature on the effects of the recent reforms.

\subsection{History and past policy measures until the end of the 1990's}

The employees' disability insurance law called WAO was introduced in 1967. It integrated schemes for occupational diseases and work injuries ('risque professionnel') and other disability causes ('risque social'), combining the generosity of risque professionnel schemes with a broad risk definition as common in risque social schemes. The benefit level was not means-tested and did equal $70 \%$ of the previous wage. In addition, in 1976 the Wajong scheme for young disabled (individuals who become disabled before the age 18 and therefore had no chance to access the regular WAO scheme) was introduced. ${ }^{2}$ Due to a recent rise in the number of young disabled this Wajong scheme recently underwent reform by pushing reintegration and still is high on the political agenda. The current government has proposed that from 2012 onwards the Wajong will only be accessible for those without any working capacity.

\footnotetext{
${ }^{2}$ In 1976 also a scheme for self-employed was introduced. However, this scheme was privatized in 2004.
} 
After the introduction, the number of beneficiaries in the WAO grew rapidly and soon the scheme was found to be unmanageable. In fact, as De Jong (2008) concludes, the WAO was misused twice to accommodate social change. Firstly, during the 1970 s and 1980 s the scheme supported the change from an industrial to a service oriented society. Massive lay-offs in the industrial sector were partly transferred to the disability scheme, which provided a generous benefit. The WAO started to function as an early retirement route (see also de Vos and Kapteyn, 1997). Secondly, according to De Jong (2008), during the 1990s the WAO supported Dutch households in their transformation from a traditional single breadwinner type to a modern dual earner type as women had a higher chance to get a disability benefit.

Already since the early 1980 s several policy measures had been introduced in an attempt to reduce the number of benefits. During the early 1980s the level of the disability benefits was decreased. Replacement rates fell from $90 \%$ to $75 \%$ but were still extremely high by international standards, in particular for non-work-related injuries. Until 1987, the partially disabled were allowed full benefits, accommodating a lot of hidden unemployment within the scheme (Koning and Van Vuuren, 2010). In 1991 a controversial scheme of premiums and fines for employers based on their disability benefit inflow was introduced. In 1993, after political turmoil, a new law was adopted that proved to be the first really successful reform. From then on at the entry examination all possible job alternatives were taken into account. As a consequence, inflow into the disability scheme dropped substantially from 93,000 in 1993 to 64,000 in 1995. Also, all the existing disability benefit recipients were re-examined, those aged 45 and below against the new criteria. Finally a two-phase benefit system was introduced, starting with a wage-related benefit followed by a lower, age-dependent follow-up benefit. However, the new entrance criteria were considered by many to be too strict and a lot of negative publicity enforced the Minister of Social Affairs to instruct the benefit administration office to relax the entrance criteria in practice. Moreover, the two phases benefit system never really worked in practice because employers and employees organizations agreed on additional insurances covering the gap between the initial wage-related benefit and the follow-up benefit. From 1996 on, inflow started rising again very rapidly until a new record high in 2001 of 104,000 new entries. OECD (2003) concluded that the Netherlands was among the OECD members with the highest rates of disability benefit recipiency and inflow of new recipients. In particular, the high inflow rates of women and the high overall benefit recipiency among the elderly were considered worrying given the oncoming ageing of the population. 


\subsection{Recent policy changes}

Since 1998 the following major policy reforms in the employees' disability scheme have been implemented:

- Experience rating (1998). Until 1998 all employers paid a fixed premium rate for the disability scheme, regardless of the number of disability cases they had ${ }^{3}$. Since 1998 two separate premium rates exist, one differentiated rate covering the first five years of disability and one fixed rate covering the cost of the later years. The differentiated premium is based upon the firm-specific disability costs of year ( $t-2)$. The experience rating system was introduced in five steps, increasing the average differentiated premium to its structural level in $2003^{4}$. Meanwhile the experience rating has been extended to ten years but the permanently fully disabled are exempted.

- Gatekeeper protocol (2002). This protocol, in force from April 2002, specifies the legal responsibilities of both the incapacitated employee and the employer. After eight weeks of absence, the employer and employee together should have made a vocational rehabilitation plan specifying the pathway to recovery (if possible). If later on a disability benefit is claimed, a rehabilitation report should be provided containing the original rehabilitation plan and the steps followed since. If reintegration efforts are considered insufficient the disability claim is dismissed.

- Stricter examination criteria (2004). From 1 October, 2004 onwards, the entrance criteria to the WAO were tightened. This change was originally meant to be part of the WIA, but came into force earlier, capturing the last quarter of the WAO inflow. The changes were mainly technical, including decreasing the minimum number of job alternatives that have to be found in order to determine the grade of partial disability and increasing the number of job alternatives for part-time workers (until 2004 full-time jobs were not taken into account in determining their grade of disability).

- Re-examinations of the disability stock (2004-2009). Using the same tightened examination criteria, a large part of the existing disability stock was re-examined between October 1, 2004 and April 1, 2009. Originally all disability benefit recipients younger than 55 in 2004 were

\footnotetext{
${ }^{3}$ The Dutch employees' disability benefit scheme is financed by employers by paying a premium on their employees' wages.

${ }^{4}$ In 2003, the experience rating system was abolished for small employers. However, experience rating was reintroduced for small employers from 2006 onwards in the WIA-law.
} 
meant to be re-examined but under political pressure this age limit was decreased in two steps to all people younger than 45 in 2004. At the same time, from October 1, 2004 onwards, the re-examination procedure for the disability stock was changed. Instead of 'mechanical' reexaminations after the first, fifth and tenth year of the benefit, the benefit administration office was given freedom in determining whom to re-examine and when.

- WIA-scheme (2006). The WIA reform itself introduced two different schemes: one generous scheme (called IVA) without re-examinations for the fully disabled who have no chance of recovery and one less generous scheme (called WGA) for the partially disabled and the fully disabled with some chance of recovery. The WGA involves frequent re-examinations and consists of two phases. During the first phase, which lasts as long as the unemployment benefit would have lasted, the benefit height equals the unemployment benefit. ${ }^{5}$ During the second phase, a wage subsidy is paid to those who work to a sufficient level according to their abilities, but only a minimum benefit is paid to those who do not. In addition, for the WGA it is possible to opt out for a private insurer. Furthermore, the minimum grade of disability in the WIA scheme is $35 \%$ instead of $15 \%$ in the WAO. Preceding the WIA, in 2004, the waiting period for entrance into the disability scheme was extended from 1 to 2 years in order to increase the direct financial incentive for employers. During this period of incapacity, employers have full responsibility for paying their employees, so there is a strong incentive for reintegration. In addition, a financial incentive was created for employees to return to work by limiting the sick pay during the second year of incapacity to $70 \%$ of the wage instead of the average of $90 \%$ that was common until then.

These are the major policy changes that have taken place since 1998. They have in common that they actually changed the disability insurance law and that they directly affect the disability schemes. The decrease of the disability inflow since then has been impressive (see Figure 1). Current inflow levels are about $40 \%$ the level of around the turn of the century. OECD (2008) concludes that this success is a consequence of a series of very comprehensive reforms, characterised by a shift of responsibilities to employers and employees, a tightening in benefit eligibility and generosity, and a (partial) privatisation of public schemes.

\footnotetext{
${ }^{5}$ In the Netherlands the maximum duration of unemployment benefit is three years and two months.
} 
Figure 1: Disability (WAO+WIA) stock (left axis) and inflow (right axis), 1968-2010

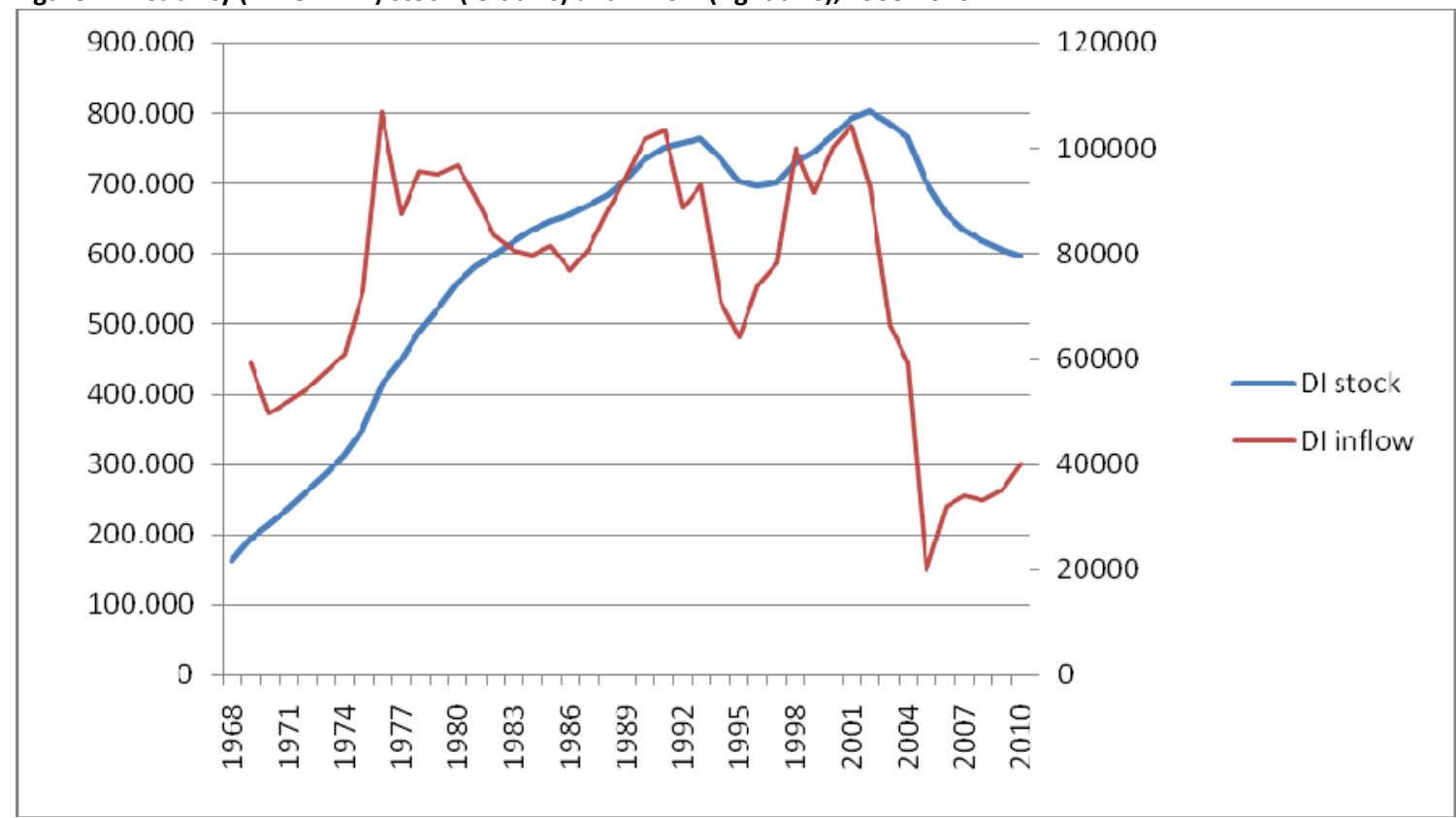

The thick line shows the disability stock that topped the 800,000 level in 2002 . The thin line shows the inflow level that is down from around 100,000 a year around the turn of the century to around 40,000 in 2010, although it can be seen that inflow is following an upward trend during recent years.

\subsection{Earlier literature}

There is a substantial body of literature on the effects of individual disability reforms. Koning (2009) finds a $15 \%$ reduction of experience rating on WAO inflow, based on an analysis of micro data from 2000 to 2002. Zwinkels (2007) finds an additional effect of the introduction of private insurers to the disability insurance market. Employers who opt out of the public system reduce their inflow by $11 \%$. The impact of the gatekeeper protocol on WAO inflow is estimated to be about half of the $43 \%$ inflow reduction between 2001 and 2004 by De Jong, Thio and Bartelings (2005). These researchers also explain a smaller part of the inflow reduction from the business cycle: disability inflow decreases when unemployment is higher. Stegeman (2005) also finds a procyclical relation, where economic upswings go together with more absence due to illness. Possibly during good times people are less afraid of losing their jobs when getting ill. However, the literature on the relationship between sickness and disability benefit use and the business cycle is ambiguous. Benitez-Silva et al. (2010) report evidence of higher total enrolments, lower outflows and, often, higher inflows into disability rolls in periods of above-average unemployment suggesting the disability schemes being used to cover unemployment risks in bad 
economic times. This confirms experiences from the Netherlands in the 1980 's. The impact of the stricter examination criteria is quantified by Van Deursen and Mulders (2009) and estimated to reduce inflow by $9 \%$. The WIA itself (including the extension of the sickness period) reduces inflow by $38 \%$ in terms of inflow level 2004 or $21 \%$ in terms of inflow level 2000 (Berendsen, Mulders and Van Loo, 2007), mainly because of the lower number of claims because of the extension of the sickness period and the increased entrance level. On outflow-related policy measures Van der Burg and Prins (2010) conclude that between 2005 and 2009, 345,000 WAO beneficiaries were re-examined. For 110,000 beneficiaries the re-examination caused a decrease or termination of the benefit.

\section{Data and model}

The data used in this analysis - micro datasets of the disability schemes since 1999 - were supplied by UWV, the benefit administration office. The datasets contain both the flows (all benefits that started or terminated during the year) and the stock of benefits by the end of the year. Although the administrative data sources are complete and accurate, the data are limited to the variables that are needed for determining and paying the benefit. These include, among others, birth date, wage, grade of disability, start date and termination date of the benefit.

The datasets for the WAO-scheme are available for 1999-2010. The datasets for the WIAscheme are available for 2006-2010. Because exact dates of the inflows and outflows are known, quarterly data can be constructed from the yearly datasets. This helps to overcome the problem of a yearly time series that is too short given the number of explanatory variables ${ }^{6}$. Also, the time series is corrected for administrative disturbances. This procedure is described in appendix $A$.

Figure 2 shows the development of the inflow rate over time. When studying the inflow rate, some important shifts can be seen, especially in 2002 and 2003 and between 2004 and 2006. This suggests a large impact from the gatekeeper protocol (started in 2002Q2) and the WIA (started in 2006Q1) and less impact from experience rating (started in 1998Q1) and the stricter entrance examinations (started in 2004Q4). When measured in fully disabled equivalents (fde), the WIA effect is smaller (see thin line). The effect of the WIA reform is mainly caused by the abolition of the two lower classes of disability. This excludes beneficiaries with a low grade of

\footnotetext{
${ }^{6}$ All regressions have been performed as well using monthly data instead of quarterly data, in order to extend the time series further. However these analyses yielded similar results.
} 
disability only. From 2006 onwards, the inflow rate in fde is almost equal to the inflow rate in persons, because of a significant rise in the average grade of disability.

Figure 2: WAO+WIA inflow rate (\% working population) on cohort basis, 1999Q1-2010Q3

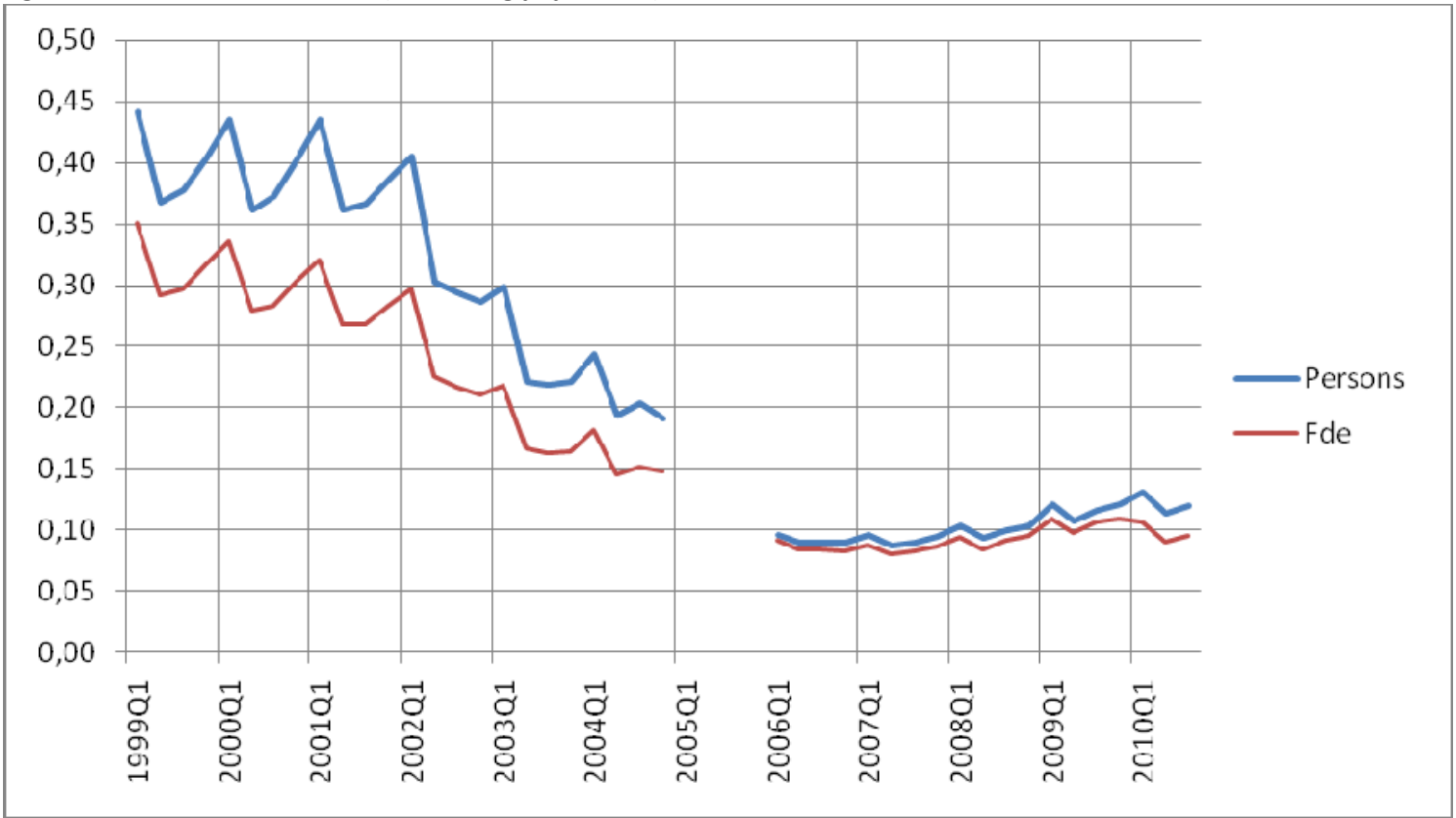

Figure 3 shows the development of the corrected outflow rate over time. Outflow because of demographic reasons (pensioning and mortality) is excluded because this outflow is not influenced by the policy reforms in this period.

Figure 3: WAO+WIA outflow rate (\% DI stock excluding pensioning and mortality) on cohort basis, 1999Q1-2010Q3

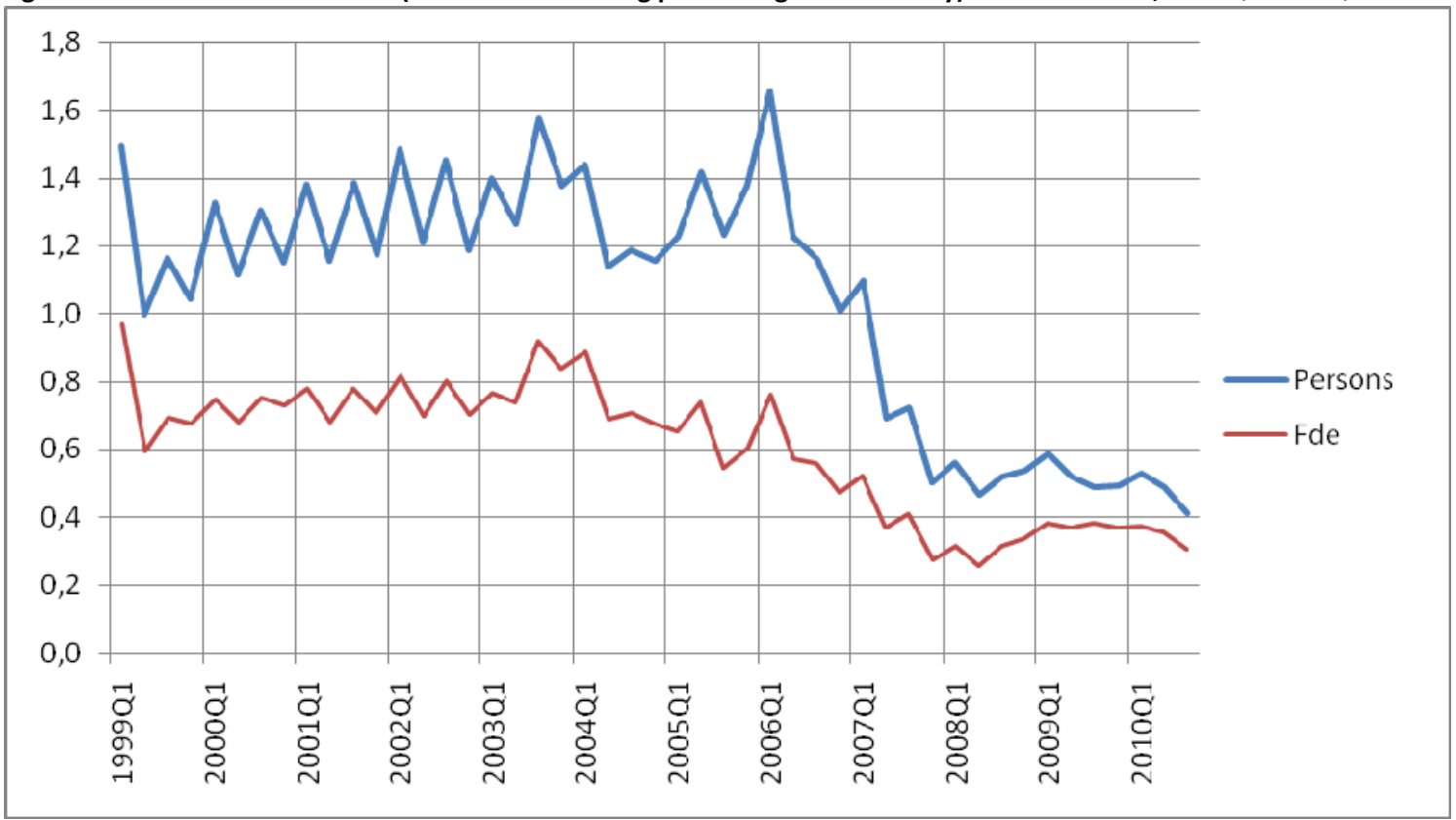


Outflow rates are rather stable from 1999 until 2003 and decrease slightly in 2004. Outflow rates then increase substantially from the first quarter of 2005 onwards, a consequence of the reexaminations taking place at that time. However, the effect of the re-examinations seems to fade out after a while. Already during 2006, outflow rates drop below the 2004 levels. In 2009 and 2010, outflow rates are down to less than half the level of the beginning of the century.

From the international literature, it can be concluded that the structure of the disability program itself (benefit level, entrance criteria etc.) and its interaction with the labour market are the central factors explaining the number of disability benefits (see for example Autor and Duggan (2006, pp. 85)). Health and ageing appear to be comparatively minor factors. Therefore, we explain the inflow and outflow rates from a set of explanatory variables including policy variables for the disability program, business cycle and seasonal effects. Moreover, separate analyses are performed on the relevant demographic subgroups in order to examine whether the different policy measures have different gender or age effects.

The dependent variable in the inflow model is the inflow rate. Until 2004 the inflow rate in (t) equals the inflow in ( $t$ ) over the insured population in (t-1). From 2006 onwards, the inflow rate in $(t)$ equals the inflow in $(t)$ over the insured population (the employees) in $(t-2)$ as the period of incapacity is extended from one to two years in 2004, so the new beneficiaries in 2006 had their first day of incapacity in 2004. The working population excluding the self-employed is used as a proxy for the insured population.

For the explanatory variables we first define four main inflow-related policy measures as described in section 2.2: experience rating, the gatekeeper protocol, stricter examinations and the WIA reform. The policy variables are 0 when the policy measure is not yet effective and 1 when the measure is fully effective. In the case of experience rating, the value of the policy variable is incrementally increased from 0 to 1 between 1998 and 2003 as the premium rates were increased stepwise to a structural level. The step sizes are based on the average premium level. The value of this policy variable is 1 after 2003 because experience rating has been institutionalized since 2003. However, mean premium rates fell after 2003, mainly because of decreasing inflow. Therefore, a variable is added representing the change in annual premium rate since 2003. In the case of the gatekeeper protocol, the value of the policy variable is stepwise increased from 0 to 1 between the second quarter of 2002 and the second quarter of 2003. As this measure affects all sick employees, those who became incapacitated in the second quarter of 
2002 (and entered the disability scheme in the second quarter of 2003) were the first to be fully affected by the measure. The stricter examinations and the WIA reform became effective immediately. The regression model will also test for increasing or decreasing effectiveness of the gatekeeper protocol and the WIA law by including cross-terms of the policy variables and the time. It can be argued, for example, that on the one hand it takes time for employers to get used to the gatekeeper protocol so that effectiveness increases over time. On the other hand, it can also be argued that after using the protocol for a while attention decreases so that effectiveness decreases over time.

Among the explanatory variables we include a business cycle indicator. We tested two business cycle indicators: the unemployment rate and a composite business cycle indicator as supplied by De Nederlandsche Bank (DNB), which captures both unemployment and confidence indicators of producers and consumers (Den Reijer, 2006). Because there is a considerable lag between the first day of incapacity and the inflow into the disability scheme (one year until 2004 and two years afterwards), in the inflow model we use the mean value of the indicator in the quarter of the first day of incapacity and the quarter of entry into the disability scheme as a proxy for the average labour market situation during the incapacity period before entering the disability scheme. Both business cycle indicators were found to perform about as well. We choose the DNB indicator instead of the unemployment rate for the disability scheme analyses because disability benefits cover a longer time span in which future expectations may play a role. An overview of the values of the policy variables and the business cycle indicator is included in appendix B.

When using quarterly inflow data we do have to include seasonal dummies because there is a clear seasonal pattern with the highest level in the first quarter and the lowest level in the third quarter (see figure 2). This may be a logical consequence of entry into the disability scheme taking place exactly one year after the first day of sick leave. As sick leave levels are higher in winter and lower in summer, this pattern also appears in the disability inflow. However, it also seems that as inflow decreases, the seasonal effect is becoming smaller. Therefore, we introduce cross-terms of the seasonal dummies and the degree of inflow reduction. The model (1) results:

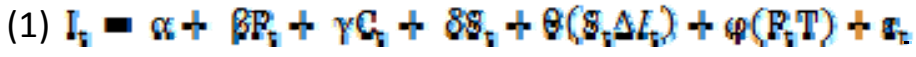

where $I_{t}$ represents the inflow rate, $P_{t}$ represents a vector of inflow-related policy variables (experience rating, gatekeeper, stricter examinations and WIA reform), $C_{t}$ represents the business 
cycle variable, $S_{t}$ represents a vector of seasonal dummies, $S_{t} \Delta I_{t}$ represents the cross term of the seasonal dummies and the variable $\Delta I_{t}$ representing the degree of inflow reduction in $t$ as compared to the base year (1999) and $P_{t} T$ represents the cross term of the policy variables and the time.

The dependent variable in the outflow model is the outflow rate (excluding outflows because of mortality and pensioning). The outflow rate in (t) equals the outflow in (t) over the DI stock in (t). The explanatory variables include the outflow-related policy variables, a business cycle variable, seasonal dummies and, because outflow through recovery is most likely to take place for those who just entered the scheme, a variable representing the average inflow rate of the previous eight quarters.

Of the inflow-related policy measures, only experience rating is included as an outflowrelated policy measure as well because employers can reduce their premium by re-integrating disability benefit recipients. Experience rating indeed was intended both to reduce inflow (by preventive measures) and to increase outflow (by re-integrative measures). An important and controversial outflow-oriented policy measure is the re-examination of the disability stock against the new tighter entrance criteria. This re-examination programme was running between October 2004 and April 2009. At the same time the re-examination programme started, the general reexamination procedure for the disability stock was changed. Instead of 'mechanical' reexaminations after the first, fifth and tenth year of the benefit, the benefit administration office was given complete freedom in determining who to re-examine and when. Although both measures were introduced at the same time and the re-examinations were finished only just before the end of the observation period, it is possible to give an indication of the separate effects. The impact of the re-examination operation was reduced in 2007, when a new government took office and the age limit was reduced from 50 to 45 years. People aged between 45 and 50 were re-examined after all, but based upon the old examination and less stricter criteria. Those who had been re-examined already could re-enter the disability benefit scheme. As a consequence, from the second quarter of 2007 onwards, the benefit administration office focused on correcting the re-examinations of beneficiaries aged 45 and over that already had taken place so that the re-examinations more or less came to a halt for a while. Therefore, the values of the policy variable are based on the number of re-examinations per quarter, with the 
maximum value in the last quarter of 2005 when the most re-examinations were performed ${ }^{7}$. Furthermore, a cross-term is included of the re-examination operation policy variable and the time period in order to reflect changes in strictness during the re-examination operation, as it is known from the benefit administration office (UWV, 2008) that the effects of the re-examinations decreased during the operation.

The quarterly outflow data also show a clear seasonal pattern with peaks in the first and third quarter of each year (figure 3). A possible explanation for the third quarter peaks is the availability of seasonal labour in summer, which increases the chances of rejoining the labour market for disability benefit recipients. Higher outflow rates in winter seem to have mainly administrative reasons like higher inflow in winter causing higher outflow in winter because the first re-examination used to take place one year after inflow. The model (2) results.

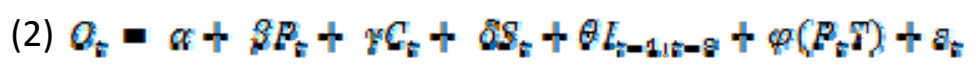

where $O_{t}$ represents the outflow rate, $P_{t}$ represents a vector of outflow-related policy variables (experience rating, re-examinations $\mathrm{DI}$ stock and the change of the re-examination system), $C_{t}$ represents the business cycle variable, $S_{t}$ represents a vector of seasonal dummies, $I_{t-1 ; t-8}$ represents the average inflow rate of the previous eight quarters and $P_{t} T$ represents the cross term of the policy variable representing the re-examinations of the DI stock and the time.

\section{Estimation results}

In this section the immediate effects on disability inflow and outflow of the individual policy measures since the late 1990s are disentangled. Regression analyses are performed for the inflow and outflow rates in both persons and fde-equivalents.

In both inflow models, first order autocorrelation is present. OLS estimates yielded Durbin-Watson statistics of 0.86 and 0.84 respectively. Autocorrelation is corrected for using the Yule-Walker method of generalized least squares (GLS, see Gallant and Goebel (1976)). Table 1 gives the GLS model estimates for the general models of the inflow rate.

\footnotetext{
${ }^{7}$ The policy variable equals 0 in the last quarter of 2004. Although re-examinations already took place during that quarter, benefits were only terminated a minimum of two months after the re-examination, so that almost no benefits were actually terminated during that $4^{\text {th }}$ quarter of 2004.
} 
Table 1: GLS estimates inflow model ( $N=43)$

\begin{tabular}{|c|c|c|}
\hline & Persons & Fde \\
\hline Intercept & $0.461(0.018) * * *$ & $0.372(0.014) * * *$ \\
\hline Experience rating & $-0.059(0.024) *$ & $-0.078(0.019) * * *$ \\
\hline Premium rate & $-0.007(0.010)$ & $-0.001(0.008)$ \\
\hline Gatekeeper protocol & $-0.114(0.018) * * *$ & $-0.082(0.014) * * *$ \\
\hline Gatekeeper protocol * Time & $-0.007(0.002) * *$ & $-0.005(0.002) *$ \\
\hline Stricter examinations & $-0.018(0.009) *$ & $-0.009(0.007)$ \\
\hline WIA & $-0.097(0.017) * * *$ & $-0.055(0.014) * * *$ \\
\hline WIA * Time & $0.010(0.002) * *$ & $0.006(0.002) * *$ \\
\hline Business cycle indicator & $0.007(0.007)$ & $0.004(0.006)$ \\
\hline Quarter 2 & $-0.078(0.003) * * *$ & $-0.057(0.003) * * *$ \\
\hline Quarter 3 & $-0.067(0.004) * * *$ & $-0.051(0.003) * * *$ \\
\hline Quarter 4 & $-0.041(0.004) * * *$ & $-0.033(0.003) * * *$ \\
\hline Quarter $2 *$ Inflow reduction & $0.087(0.007) * * *$ & $0.062(0.005) * * *$ \\
\hline Quarter $3 *$ Inflow reduction & $0.076(0.009) * * *$ & $0.060(0.007) * * *$ \\
\hline Quarter $4 *$ Inflow reduction & $0.041(0.008) * * *$ & $0.036(0.007) * * *$ \\
\hline $\mathrm{R}^{2}$ & 0.998 & 0.997 \\
\hline Dw & 1.90 & 1.89 \\
\hline
\end{tabular}

The regression on inflow in persons shows that all four policy variables have significantly reduced the inflow rate. Estimates are $13 \%$ for experience rating $\left(0.059 / 0.461^{8}\right), 25 \%$ for the gatekeeper protocol, $4 \%$ for the stricter examinations and $21 \%$ for the WIA-scheme. There is no significant effect of the premium rate in the experience rating system after 2003, but there is a significant time trend in the effectiveness of gatekeeper protocol and WIA: gatekeeper is becoming more effective and WIA is becoming less effective. The business cycle has no significant influence on the inflow. The seasonal dummies all have significant negative values. As the cross-terms of seasonal dummies and inflow reduction have significant positive values in the same order of magnitude, the seasonal trend indeed did almost disappear in 2006 and 2007 when inflow levels hit their lowest level.

Similar results follow from the regression on inflow in fde with higher estimates for experience rating (21\%) and lower estimates for gatekeeper (22\%), stricter examinations (3\%) and WIA (15\%). The combined policy measures have reduced inflow in persons by $63 \%$ and inflow in fde by $61 \%$. The three measures introduced until 2004 reduced inflow in persons by $42 \%$ and inflow in fde by $46 \%$, so already before the WIA reform in 2006, inflow was down by between 40 and $50 \%$ as a result of the earlier policy reforms.

\footnotetext{
${ }^{8} 0.461$ is the inflow rate in the $1^{\text {st }}$ quarter when all policy measures are ineffective and the business cycle indicator equals 0 .
} 
We repeat the former analysis for age- and gender-specific subgroups. We distinguish four groups: men aged below 45, men aged 45 and over, women aged below 45 and women aged 45 and over. Again, autocorrelation is corrected for using the Yule-Walker method of GLS. For convenience, the results are limited to the inflow rate in persons (see table 2).

Table 2: GLS estimates inflow models for men and women aged 45 and over and below 45 respectively ( $N=43$ )

\begin{tabular}{|c|c|c|c|c|}
\hline & Men $<45$ & Men >= 45 & Women < 45 & Women >= 45 \\
\hline Intercept & $0.220(0.007) * * *$ & $0.644(0.024) * * *$ & $0.516(0.020) * * *$ & $1.149(0.033)^{* * *}$ \\
\hline Experience rating & $-0.034(0.010) * *$ & $-0.088(0.033) *$ & $-0.110(0.027) * * *$ & $-0.176(0.043) * * *$ \\
\hline Premium rate & $-0.002(0.005)$ & $-0.019(0.017)$ & $-0.010(0.012)$ & $-0.015(0.030)$ \\
\hline Gatekeeper protocol & $-0.048(0.008) * * *$ & $-0.145(0.029) * * *$ & $-0.142(0.021) * * *$ & $-0.377(0.037) * * *$ \\
\hline Gatekeeper protocol * Time & $-0.002(0.001) *$ & $-0.011(0.003) * *$ & $-0.006(0.002) *$ & $-0.021(0.005) * * *$ \\
\hline Stricter examinations & $-0.008(0.005)$ & $-0.006(0.017)$ & $-0.021(0.012) *$ & $-0.028(0.037)$ \\
\hline WIA & $-0.054(0.008) * * *$ & $-0.147(0.028) * * *$ & $-0.110(0.021) * * *$ & $-0.158(0.047) * *$ \\
\hline WIA * Time & $0.004(0.001)^{* *}$ & $0.015(0.003) * * *$ & $0.008(0.003) *$ & $0.026(0.005)^{* * *}$ \\
\hline Business cycle indicator & $-0.001(0.003)$ & $0.007(0.010)$ & $0.010(0.008)$ & $0.002(0.013)$ \\
\hline Quarter 2 & $-0.021(0.002) * * *$ & $-0.118(0.007) * * *$ & $-0.072(0.004) * * *$ & $-0.258(0.019) * * *$ \\
\hline Quarter 3 & $-0.013(0.002) * * *$ & $-0.099(0.008) * * *$ & $-0.066(0.005) * * *$ & $-0.222(0.019) * * *$ \\
\hline Quarter 4 & $-0.007(0.002) * *$ & $-0.059(0.008) * * *$ & $-0.044(0.005) * * *$ & $-0.139(0.019) * * *$ \\
\hline Quarter $2 *$ Inflow reduction & $0.023(0.004) * * *$ & $0.125(0.014) * * *$ & $0.086(0.009) * * *$ & $0.303(0.037) * * *$ \\
\hline Quarter $3 *$ Inflow reduction & $0.016(0.004) * *$ & $0.106(0.016) * * *$ & $0.083(0.011) * * *$ & $0.263(0.037) * * *$ \\
\hline Quarter $4 *$ Inflow reduction & $0.006(0.004)$ & $0.045(0.015)^{* *}$ & $0.051(0.011) * * *$ & $0.142(0.038) * * *$ \\
\hline $\mathrm{R}^{2}$ & 0.997 & 0.996 & 0.998 & 0.995 \\
\hline Dw & 2.02 & 2.18 & 1.79 & 1.79 \\
\hline
\end{tabular}

For experience rating and the gatekeeper protocol, we find a higher impact among both older and younger women. This could be a consequence of the inflow rates among women being well above those of men in the beginning of the observation period, so that the highest gains from an active re-integration approach of employers could be made among women. The impact of the stricter examinations is similar for men and women. The impact of the WIA is higher among men. This is in line with the observation that men have a higher chance of receiving a partial disability benefit as in the WIA the minimum grade of disability was raised from $15 \%$ to $35 \%$. In all four models the effect of the gatekeeper protocol increases over time and the effect of the WIA decreases over time. All four models have insignificant values of the business cycle indicator.

Finally, the former analyses on inflow are repeated for specific sectors of economic activities. UWV distinguishes 69 different sectors. They are aggregated into ten main groups, based on the International Standard Industrial Classification of All Economic Activities used by Statistics Netherlands, and for which detailed information on the insured population is available. 
These sectors can be expected to have different incentives from the recent policy measures. Intuitively, one would expect the experience rating to be less effective in the public sector, which experiences a less direct and less accountable effect of higher premiums. The gatekeeper protocol can be expected to affect sectors with larger employers the most, because they can more easily deal with the administrative requirements of this law. The sector results are presented in table 3. For convenience, the results are limited to the inflow rate in persons and the seasonal dummies (that follow the same pattern as in tables 1 and 2) are excluded from the table.

Table 3: GLS estimates sector inflow models $(\mathrm{N}=43)$

\begin{tabular}{|c|c|c|c|c|c|}
\hline & Construction & $\begin{array}{l}\text { Financial / } \\
\text { business }\end{array}$ & Health care & $\begin{array}{l}\text { Public sector / } \\
\text { education }\end{array}$ & Flexi work \\
\hline $\begin{array}{l}\text { Intercept } \\
\text { Experience rating } \\
\text { Premium rate } \\
\text { Gatekeeper protocol } \\
\text { Gatekeeper protocol * Time } \\
\text { Stricter examinations } \\
\text { WIA } \\
\text { WIA * Time } \\
\text { Vacancy rate }\end{array}$ & $\begin{array}{l}0.383(0.011) * * * \\
-0.085(0.012) * * * \\
-0.000(0.008) \\
-0.048(0.009) * * * \\
-0.006(0.001) * * * \\
-0.011(0.010) \\
-0.080(0.012) * * * \\
0.006(0.001) * * * \\
-0.000(0.000) \\
\end{array}$ & $\begin{array}{l}0.160(0.009) * * * \\
0.007(0.012) \\
-0.012(0.007) * \\
-0.048(0.008)^{* * *} \\
-0.005(0.001)^{* *} \\
-0.000(0.006) \\
-0.047(0.011)^{* * *} \\
0.006(0.001) * * * \\
0.000(0.000)\end{array}$ & $\begin{array}{l}0.657(0.034) * * * \\
-0.170(0.039) * * * \\
0.001(0.018) \\
-0.192(0.029) * * * \\
-0.011(0.004) * * \\
-0.025(0.018) \\
-0.063(0.029) * \\
0.014(0.004) * * \\
-0.001(0.001) \\
\end{array}$ & $\begin{array}{l}0.433(0.043) * * * \\
-0.034(0.056) \\
-0.003(0.022) \\
-0.163(0.035) * * * \\
-0.005(0.005) \\
-0.030(0.021) \\
-0.100(0.035) * * \\
0.007(0.006) \\
0.000(0.001) \\
\end{array}$ & $\begin{array}{l}0.367(0.023) * * * \\
-0.030(0.021) \\
-0.009(0.022) \\
-0.126(0.017) * * * \\
0.002(0.003) \\
-0.019(0.017) \\
-0.137(0.020) * * * \\
0.002(0.003) \\
0.000(0.000) \\
\end{array}$ \\
\hline $\begin{array}{l}\mathrm{R}^{2} \\
\text { Dw } \\
\# \text { employees in sector }\end{array}$ & $\begin{array}{l}0.996 \\
2.12 \\
389,000\end{array}$ & $\begin{array}{l}0.993 \\
1.97 \\
1,232,000\end{array}$ & $\begin{array}{l}0.998 \\
2.08 \\
1,155,000\end{array}$ & $\begin{array}{l}0.989 \\
2.00 \\
908,000\end{array}$ & $\begin{array}{l}0.988 \\
1.48 \\
519,000\end{array}$ \\
\hline & Agriculture & Manufacturing & Trading & Transportation & $\begin{array}{l}\text { Hotels / } \\
\text { restaurants }\end{array}$ \\
\hline $\begin{array}{l}\text { Intercept } \\
\text { Experience rating } \\
\text { Premium rate } \\
\text { Gatekeeper protocol } \\
\text { Gatekeeper protocol * Time } \\
\text { Stricter examinations } \\
\text { WIA } \\
\text { WIA * Time } \\
\text { Vacancy rate }\end{array}$ & $\begin{array}{l}1.156(0.055) * * * \\
-0.397(0.062) * * * \\
-0.033(0.039) \\
-0.295(0.049) * * * \\
-0.021(0.007) * * \\
-0.024(0.051) \\
-0.134(0.058) * \\
0.032(0.009) * * \\
0.003(0.001)^{*}\end{array}$ & $\begin{array}{l}0.342(0.009) * * * \\
-0.068(0.009) * * * \\
-0.010(0.009) \\
-0.071(0.007) * * * \\
-0.003(0.001)^{*} \\
-0.007(0.008) \\
-0.084(0.009) * * * \\
0.005(0.001) * * \\
-0.000(0.000)\end{array}$ & $\begin{array}{l}0.294(0.008) * * * \\
-0.059(0.007) * * * \\
-0.010(0.005)^{*} \\
-0.074(0.005)^{* * *} \\
-0.002(0.000)^{* *} \\
-0.005(0.006) \\
-0.067(0.007) * * * \\
0.004(0.000) * * * \\
0.000(0.000)\end{array}$ & $\begin{array}{l}0.337(0.022) * * * \\
-0.061(0.021) * * \\
-0.011(0.010) \\
-0.082(0.009) * * * \\
-0.004(0.001)^{*} \\
-0.018(0.012) \\
-0.064(0.015) * * * \\
0.007(0.002) * * \\
0.000(0.000)\end{array}$ & $\begin{array}{l}0.351(0.013) * * * \\
-0.137(0.012) * * * \\
-0.001(0.009) \\
-0.055(0.009) * * * \\
-0.002(0.001) \\
0.002(0.011) \\
-0.060(0.012) * * * \\
0.003(0.001) * \\
-0.000(0.000) \\
\end{array}$ \\
\hline $\begin{array}{l}\mathrm{R}^{2} \\
\text { Dw } \\
\# \text { employees in sector }\end{array}$ & $\begin{array}{l}0.990 \\
1.59 \\
121,000\end{array}$ & $\begin{array}{l}0.997 \\
1.43 \\
892,000\end{array}$ & $\begin{array}{l}0.997 \\
1.26 \\
1,276,000\end{array}$ & $\begin{array}{l}0.993 \\
2.03 \\
445,000\end{array}$ & $\begin{array}{l}0.992 \\
1.78 \\
268,000\end{array}$ \\
\hline
\end{tabular}

The results confirm intuition. For the construction sector and the hotels and restaurants sector, the effect of experience rating is comparatively large and the effect of the gatekeeper is comparatively small. Employers in this sector seem to be very sensitive to financial incentives but lack the size or the capability to successfully implement a bureaucratic protocol like gatekeeper. On the other hand, in the financial and business sector, which has the lowest rate of inflow of 
disability recipients of all sectors, the effect of experience rating is non-existent but the effect of the gatekeeper protocol is substantial. Apparently, the large employers (banks, insurers etc.) in this sector initially were not sensitive to financial incentives given their low disability costs, but were able to reduce long-term disability through the gatekeeper protocol after all. In the health care sector, which is mainly populated by female workers, the effects of experience rating and gatekeeper were both large, but the WIA effects were comparatively smaller, which corresponds to the finding that the WIA affected men more than women. Another interesting result is the lack of effectiveness of experience rating in the public sector, which may be explained by the low financial accountability of public administration and educational organisations. However, the employers in the public sector, which tend to be large and used to bureaucracy, have been able to implement the gatekeeper protocol very successfully. The gatekeeper effect in the public sector is the highest out of all sectors. Also in the flexi work sector, the effect of experience rating is small. Employers in this sector have less influence on the sickness of their employees because they serve merely as an intermediary between the employee and the actual employer.

Also for the general outflow model regression analyses are performed for both the number of persons and the fde-equivalents. As no autocorrelation is present OLS estimates are used. Table 4 gives the model estimates for the outflow models (persons and fde).

\begin{tabular}{l} 
Table 4: OLS estimates outflow model (N=47) \\
\begin{tabular}{|l|l|l|}
\hline \multicolumn{2}{|l|}{ Persons } \\
Intercept & $1.084(0.163)^{* * *}$ & $0.765(0.093) * * *$ \\
Experience rating & $0.468(0.211)^{*}$ & $0.081(0.120)$ \\
Premium rate & $0.082(0.195)$ & $0.029(0.111)$ \\
Re-exam. DI stock & $1.376(0.152)^{* * *}$ & $0.473(0.086)^{* * *}$ \\
Re-exam. DI stock * Time & $-0.051(0.029)^{*}$ & $-0.021(0.016)$ \\
Re-examination system & $-0.415(0.146)^{* *}$ & $-0.243(0.083)^{* *}$ \\
Business cycle indicator & $-0.034(0.033)$ & $-0.034(0.018)^{*}$ \\
Mean inflow rate (t-1;t-8) & $1.841(0.701)^{*}$ & $0.679(0.399)^{*}$ \\
Quarter 2 & $-0.174(0.060)^{* *}$ & $-0.091(0.034) *$ \\
Quarter 3 & $-0.083(0.061)$ & $-0.051(0.034)$ \\
Quarter 4 & $-0.151(0.061)^{*}$ & $-0.068(0.035)^{*}$ \\
\hline $\mathrm{R}^{2}$ & 0.876 & 0.855 \\
Dw & 1.98 & 1.78 \\
\hline$* * * p-v a l u e<0.001, * * p-v a l u e<0.01, * p-v a l u e<0.1$ &
\end{tabular} \\
\hline
\end{tabular}

The results on outflow in persons show a strong upwards influence of the re-examinations of the DI stock on the outflow rate. The effect of the re-examinations of the DI stock decreases over time, although the coefficient of the cross-term is not significant in the fde model. Interestingly, 
the change of the re-examination system (abolition of the periodic re-examinations) has a significant negative impact on the outflow rate. It cannot yet be deducted from the data whether this is caused by the change of the re-examination system itself (e.g. the benefit administration office not being able adequately to select the cases to be re-examined) or by side effects of the re-examination of the DI stock (e.g. lack of capacity to perform regular re-examinations or recovered beneficiaries waiting to report to the benefit administration office until their reexamination). This result confirms earlier findings (UWV, 2006) that the number of "spontaneous" recoveries after the start of the re-examinations decreased remarkably. If the result is due to the change in the system, it might be so that the temporary gains of the reexaminations of the DI stock will be overcompensated by the losses from the abolition of the periodic re-examinations. Decreasing inflow is another significant reason for the decreasing outflow from the disability schemes. Experience rating increases recovery rates significantly in the persons model but the coefficient is not significant in the fde model, probably because employers are able to reintegrate mainly the partially disabled. The business cycle indicator is not significant in the persons model and is weakly significant in the fde model. Finally, the seasonal dummies for the second and fourth quarter both have significant negative values.

Again, we repeat the former analysis for age- and gender-specific subgroups. For convenience, the results are limited here to outflow in persons. The results are shown in table 5.

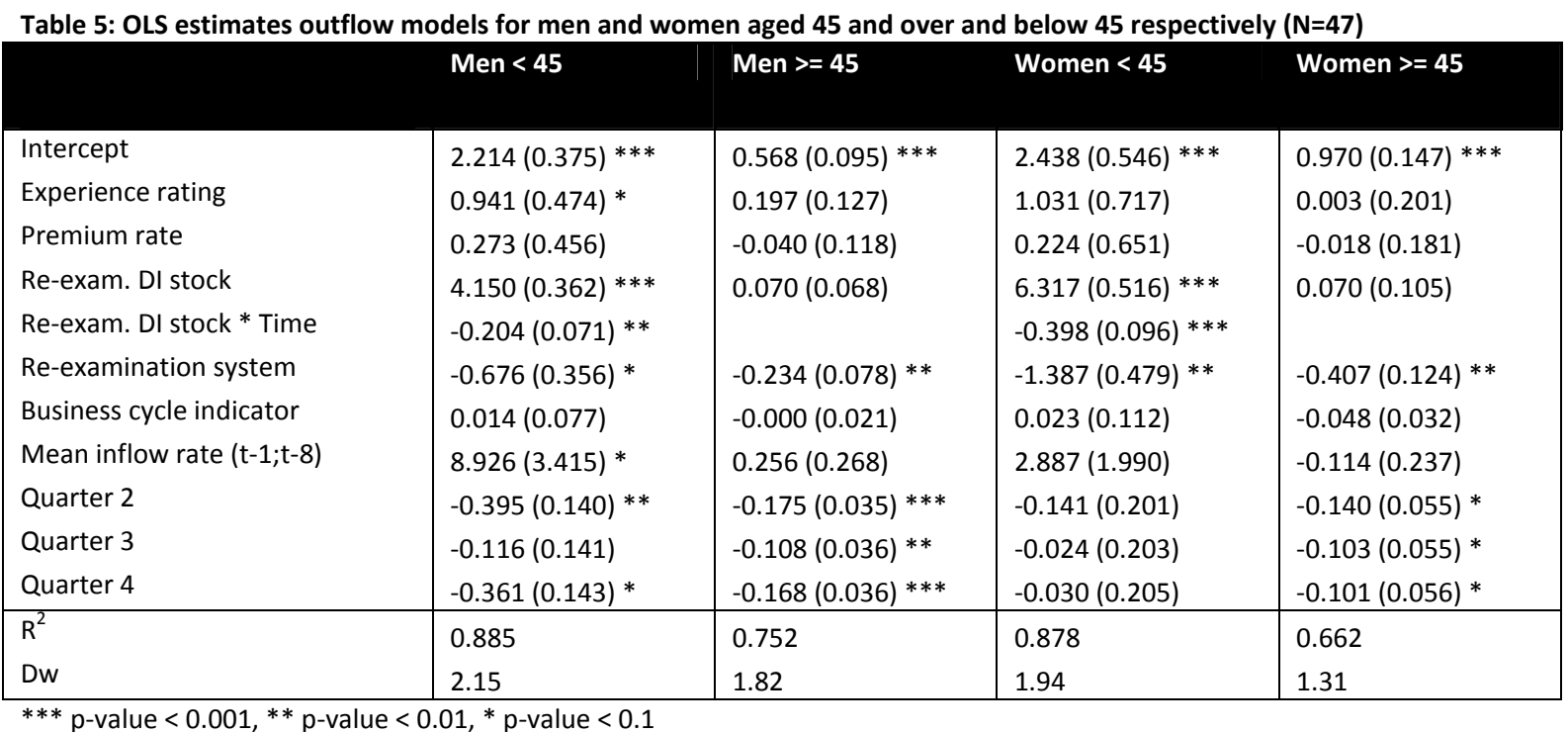

For the older men and women we include the variable on re-examinations of the DI stock because a small part of this group (the 45-50 years old) was re-examined. However, we exclude the cross-term of re-examinations and time period as we do not know the exact numbers of re- 
examinations of the elderly over time so we cannot attribute time effects to effectiveness. When considering younger men and women, the same conclusions from the overall analyses come back more pronouncedly. The re-examinations of course boost outflow in these groups, but their effect significantly decreases over time. The change in the re-examination system decreases outflow due to recovery. Among older men and women, there is no effect of the re-examinations as these were mostly exempt from it. The change in the re-examination system significantly decreases outflow because of recovery, in particular for older men and women. Again, it should be noted that it is not clear whether this effect is caused by the change itself or by side effects of the re-examinations of the DI stock. Experience rating is significant for younger men only. However, the signs of all four coefficients are positive as expected. There is no influence of the business cycle on DI outflow.

\section{Conclusions and topics for future research}

Until 2001, disability rates in the Netherlands were among the highest in the world. Major reforms took place between 1998 and 2006 causing the number of new disability claims to decrease sharply. In this paper the effects of those measures are estimated by using administrative datasets of all disability benefit recipients from 1999-2010.

It is shown that the combined policy measures have reduced inflow in persons by $63 \%$ and inflow in fde by $61 \%$. Experience rating has reduced inflow into the WAO scheme by 13 percentage points, the introduction of the gatekeeper protocol has reduced inflow by 25 percentage points and the tightening of the eligibility criteria has further reduced inflow by 4 percentage points. The additional effect of the WIA is large as well, resulting in a decrease of inflow by 21 percentage points. Interestingly, whereas the effect of the gatekeeper protocol seems to increase over time, the effect of the WIA is decreasing over time.

All these effective policy measures have one thing in common: they focus on preventing inflow. Indeed, prevention is the best way in the long run of keeping claimant numbers low. Only the re-examinations of the disability stock from 2004 to 2009 caused a significant increase in disability outflow. However, at the same time the re-examinations boosted outflow, the recovery rates of the population not affected by the re-examinations decreased sharply, possibly due to the change in the re-examination periodicity.

An important topic for future research is whether the policy reforms remain effective in the long run, especially when pressure on the disability schemes might increase in the future 
when the retirement age is raised and early retirement possibilities will be blocked. This is all the more important given the recent rise in the number of disability benefit claimants.

\section{REFERENCES}

Autor, D.H., Duggan, M.G. (2006), The Growth in the Social Security Disability Rolls: A Fiscal Crisis Unfolding, Journal of Economic Perspectives, 20, 71-96.

Benitez-Silva, H., Disney, R., Jimenez-Martin, S. (2010), Disability, capacity for work and the business cycle: An international perspective, Economic Policy, 25, 483-536.

Berendsen, E., Mulders, H., Loo, J. van (2007), Het eerste jaar WIA, Economisch Statistische Berichten, 92, 132-135.

Burg, C. van der, Prins, R. (2010), Employment instead of benefit receipt? Process and outcomes of reassessment of Dutch disability benefit recipients, European Journal of Social Security, 12, 144-155.

Cai, L., Gregory, G. (2004), Labour Market Conditions, Applications and Grants of Disability Support Pension (DSP) in Australia, Australian Journal of Labour Economics, 7, 375-394.

Den Reijer, A. (2006), The Dutch business cycle: which indicators should we monitor?, De Nederlandsche Bank, Working Paper No. 100/2006.

Deursen, C. van, Mulders, H. (2009), Schatting effect aangepaste Schattingsbesluit op aandeel afwijzingen WIA, UWV Kennismemo 09-13.

Gallant, A.R., Goebel, J.J. (1976), Nonlinear Regression with Autocorrelated Errors, Journal of the American Statistical Association, 71, 961-967.

Jones, M.K., Latreille, P.L., Sloane, P.J. (2006), Disability, gender, and the British labour market, Oxford Economic Papers, 58, 407-449.

Jong, Ph. de, Thio, V., Bartelings, H. (2005), UWV als poortwachter. Fase III: WVP en de instroom in de WAO, Ape, September 2005.

Jong, Ph. de (2008), Recent changes in Dutch disability policy, Ape, September 2008.

Koning, P.W.C. (2009), Experience Rating and the Inflow into Disability Insurance, De Economist, 157, 315-335.

Koning, P.W.C., Vuuren, D.J. van (2010), Disability Insurance and Unemployment Insurance as Substitute Pathways, Applied Economics, 42, 575-588.

OECD (2003), Transforming Disability into Ability. Policies to promote work and income security for disabled people, OECD Book. 
OECD (2008), Sickness, Disability and Work: Breaking the Barriers (Vol. 3) - Denmark, Ireland, Finland and the Netherlands, OECD Book.

Prinz, C., Tompson, W. (2009), Sickness and disability benefit programmes: What is driving policy convergence?, International Social Security Review, 62, 41-61.

Sonsbeek, J.M. van (2011), Microsimulation as a Decision Making Tool in Social Security Policy, het Zijlstra Center, VU University Amsterdam.

Sonsbeek, J.M. van, Gradus, R.H.J.M. (2010), De Beleidsmaatregelen voor de WAO gekwantificeerd, Economisch Statistische Berichten, 95, 586-588.

Stegeman H. (2005), De conjunctuurgevoeligheid van ziekteverzuim, Centraal Planbureau, 2005.

UWV (2006), UWV Kwartaal Verkenning 2006-I, Kenniscentrum UWV, April 2006.

UWV (2008), UWV Kwartaal Verkenning 2008-I, Kenniscentrum UWV, April 2008.

Zwinkels, W. (2007), Effectiviteit van re-integratie: onbenutte potenties van privatisering, Tijdschrift voor Arbeidsvraagstukken, 23, 121-131. 


\section{Appendix A: Data}

The data sources comprise all years since 1999. The datasets are corrected for administrative disturbances. This correction procedure is described in this appendix.

The dataset of new disability benefits of 1999 consists of 91,500 records. Just 74,100 $(81 \%)$ of them stem from 1999 , the remaining $19 \%$ are from earlier years. There are several reasons for this. First, there is a common overflow from one year to another. People who had their medical examination at the end of 1998 may be included in the administrative database in early 1999. Moreover, people who raise objections to the decision about their application may receive their final decision several months later than one year after their first day of sick leave. Benefits that are awarded that way will be paid retrospectively for the missed months. However, another large part of the new benefits with a starting year earlier than 1999 are people who were already in the disability scheme earlier and resumed working for a while but suffered a recurrence of the same health problem. In such a case the old benefit is resumed. We overcome these administrative influences by constructing new cohort datasets. The cohort 1999 consists of all records from the 1999 and 2000 databases that originate in 1999. Records from later databases that originate in 1999 are considered to be re-entry cases that will be left out of the analysis. This results in the following corrected year totals on cohort basis:

Table A.1: Inflow on cohort basis (WAO+WIA)

\begin{tabular}{|c|c|c|c|c|c|c|c|c|c|c|c|c|}
\hline & 1999 & 2000 & 2001 & 2002 & 2003 & 2004 & 2006 & 2007 & 2008 & 2009 & 2010 \\
\hline \multicolumn{13}{|c|}{ Persons } \\
\hline & Original & 91,517 & 100,193 & 104,142 & 92,387 & 66,335 & 59,171 & 21,051 & 22,160 & 24,947 & 29,341 & 35,641 \\
\hline & Cohort & 93,009 & 94,872 & 94,765 & 78,114 & 58,882 & 50,716 & 22,081 & 22,263 & 24,575 & 29,398 & 30,688 \\
\hline 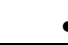 & Difference & $-1,492$ & 5,321 & 9,377 & 14,273 & 7,453 & 8,455 & $-1,030$ & -103 & 372 & -57 & 4,953 \\
\hline \multicolumn{13}{|l|}{ Fde } \\
\hline & Original & 73,135 & 77,562 & 76,583 & 67,848 & 49,015 & 44,583 & 19,886 & 20,303 & 22,787 & 27,104 & 28,513 \\
\hline & Cohort & 73,422 & 72,563 & 69,680 & 57,613 & 43,713 & 38,152 & 20,780 & 20,412 & 22,482 & 26,769 & 24,665 \\
\hline 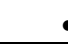 & Difference & -287 & 4,999 & 6,903 & 10,235 & 5,302 & 6,431 & -894 & -109 & 305 & 335 & 3,848 \\
\hline
\end{tabular}

In 2004, the sickness period before entering the disability benefit was extended from one to two years. Therefore, inflow into the disability scheme is extremely low in $2005^{9}$. In the other years, significant differences can be seen between the administrative inflow totals and the corrected cohort totals. For example, according to the administrative data, between 1999 and 2001, a

\footnotetext{
${ }^{9}$ Although not exactly zero. Because of the gatekeeper law from 2002, it is possible that claims for a disability benefit are rejected because reintegration efforts of the employer are considered insufficient. In such cases, claims from people that got first sick in 2003 may be awarded with some delay in 2005.
} 
significant inflow rise of almost 13,000 persons seems to have taken place, but the cohort size of the 2001 inflow cohort is only 1,700 persons larger than the 1999 inflow cohort.

For outflow, the same procedure is followed as in table A.1 on inflow. The original numbers are the numbers of outflow cases within a calendar year as reported by the benefit administration office. The quarterly cohort totals are based on the termination dates as reported in the micro data sets. All benefits that are terminated in years $(t)$ and $(t+1)$ are considered as outflow cases also tend to have a lag of on average two to three months between the termination date of the benefit and the end of the administrative process. The corrected year totals on cohort basis are presented in tables A.2 (including demographic outflow) and A.3 (excluding demographic outflow).

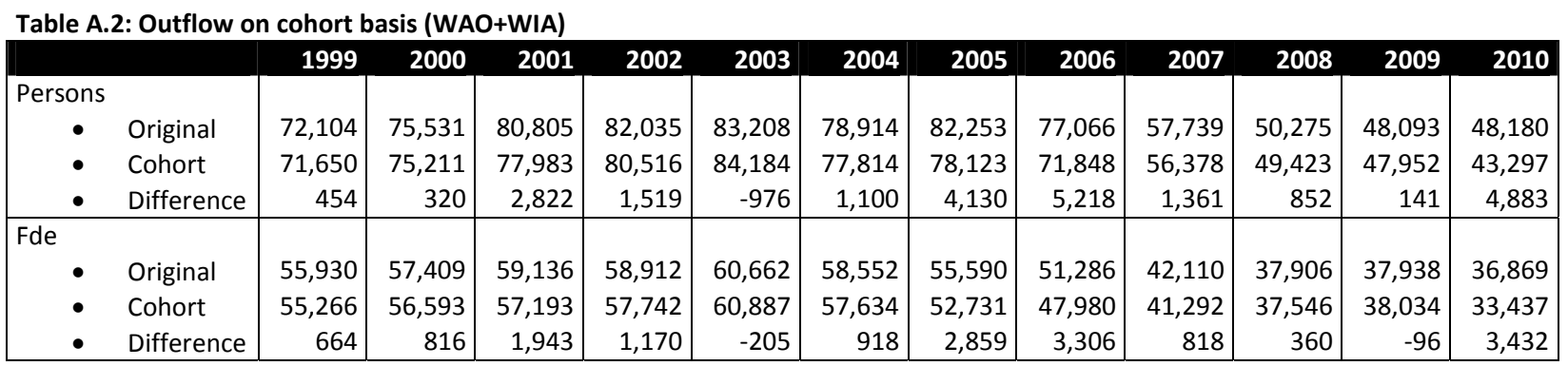

\begin{tabular}{|c|c|c|c|c|c|c|c|c|c|c|c|c|c|}
\hline & & 1999 & 2000 & 2001 & 2002 & 2003 & 2004 & 2005 & 2006 & 2007 & 2008 & 2009 & 2010 \\
\hline \multicolumn{14}{|c|}{ Persons } \\
\hline & Original & 34,470 & 37,231 & 42,513 & 43,805 & 43,945 & 39,483 & 42,867 & 38,188 & 20,849 & 13,886 & 12,733 & 14,865 \\
\hline & Cohort & 34,263 & 36,892 & 39,649 & 42,507 & 44,718 & 38,367 & 39,027 & 34,833 & 19,627 & 13,075 & 12,780 & 10,480 \\
\hline & Difference & 207 & 339 & 2,864 & 1,298 & -773 & 1,116 & 3,840 & 3,355 & 1,222 & 1,811 & -47 & 4,385 \\
\hline \multicolumn{14}{|c|}{ Fde } \\
\hline & Original & 21,821 & 22,804 & 24,893 & 24,993 & 25,963 & 23,964 & 21,468 & 17,981 & 10,968 & 8,037 & 9,100 & 10,800 \\
\hline & Cohort & 21,367 & 21,988 & 22,911 & 24,030 & 26,012 & 23,070 & 18,912 & 16,275 & 10,296 & 7,716 & 9,232 & 7,687 \\
\hline$\bullet$ & Difference & 454 & 816 & 1,982 & 963 & -49 & 894 & 2,556 & 1,706 & 672 & 321 & -132 & 3,113 \\
\hline
\end{tabular}


Appendix B: Model parameters

Table B.1: Model parameters

\begin{tabular}{|c|c|c|c|c|c|c|c|c|c|c|}
\hline Quarter & $\begin{array}{l}\text { Exp. } \\
\text { Rating }\end{array}$ & $\begin{array}{l}\text { Premium } \\
\text { rate }\end{array}$ & \begin{tabular}{|l|} 
Gate \\
keeper
\end{tabular} & $\begin{array}{l}\text { Stricter } \\
\text { examin }\end{array}$ & WIA & $\begin{array}{l}\text { Re-exam } \\
\text { DI stock }\end{array}$ & $\begin{array}{l}\text { Re-exam } \\
\text { system }\end{array}$ & \begin{tabular}{|l} 
Business \\
cycle \\
inflow
\end{tabular} & $\begin{array}{l}\text { Business } \\
\text { cycle } \\
\text { outflow }\end{array}$ & \begin{tabular}{|l|} 
Mean \\
inflow (t- \\
$1, t-8)$
\end{tabular} \\
\hline 1999Q1 & 0.36 & 0.23 & 0 & 0 & 0 & 0 & 0 & 0.627 & 0.794 & 0.398 \\
\hline 1999Q2 & 0.36 & 0.23 & 0 & 0 & 0 & 0 & 0 & 0.707 & 0.852 & 0.398 \\
\hline 1999Q3 & 0.36 & 0.23 & 0 & 0 & 0 & 0 & 0 & 0.781 & 0.908 & 0.398 \\
\hline 1999Q4 & 0.36 & 0.23 & 0 & 0 & 0 & 0 & 0 & 0.847 & 0.965 & 0.398 \\
\hline $2000 Q 1$ & 0.65 & 0.29 & 0 & 0 & 0 & 0 & 0 & 0.907 & 1.019 & 0.397 \\
\hline $2000 Q 2$ & 0.65 & 0.29 & 0 & 0 & 0 & 0 & 0 & 0.957 & 1.061 & 0.396 \\
\hline $2000 Q 3$ & 0.65 & 0.29 & 0 & 0 & 0 & 0 & 0 & 0.992 & 1.077 & 0.395 \\
\hline 2000Q4 & 0.65 & 0.29 & 0 & 0 & 0 & 0 & 0 & 1.006 & 1.048 & 0.395 \\
\hline 2001Q1 & 0.70 & 0.05 & 0 & 0 & 0 & 0 & 0 & 0.989 & 0.958 & 0.394 \\
\hline 2001Q2 & 0.70 & 0.05 & 0 & 0 & 0 & 0 & 0 & 0.929 & 0.797 & 0.393 \\
\hline 2001Q3 & 0.70 & 0.05 & 0 & 0 & 0 & 0 & 0 & 0.819 & 0.562 & 0.392 \\
\hline 2001Q4 & 0.70 & 0.05 & 0 & 0 & 0 & 0 & 0 & 0.654 & 0.260 & 0.390 \\
\hline 2002Q1 & 0.89 & 0.19 & 0 & 0 & 0 & 0 & 0 & 0.435 & -0.088 & 0.385 \\
\hline 2002Q2 & 0.89 & 0.19 & 0.125 & 0 & 0 & 0 & 0 & 0.171 & -0.456 & 0.378 \\
\hline 2002Q3 & 0.89 & 0.19 & 0.375 & 0 & 0 & 0 & 0 & -0.124 & -0.811 & 0.367 \\
\hline $2002 Q 4$ & 0.89 & 0.19 & 0.625 & 0 & 0 & 0 & 0 & -0.431 & -1.121 & 0.352 \\
\hline 2003Q1 & 1 & 0.11 & 0.875 & 0 & 0 & 0 & 0 & -0.725 & -1.362 & 0.335 \\
\hline 2003Q2 & 1 & 0.11 & 1 & 0 & 0 & 0 & 0 & -0.986 & -1.517 & 0.317 \\
\hline 2003Q3 & 1 & 0.11 & 1 & 0 & 0 & 0 & 0 & -1.196 & -1.581 & 0.298 \\
\hline $2003 Q 4$ & 1 & 0.11 & 1 & 0 & 0 & 0 & 0 & -1.341 & -1.560 & 0.278 \\
\hline 2004Q1 & 1 & -0.01 & 1 & 0 & 0 & 0 & 0 & -1.415 & -1.468 & 0.258 \\
\hline $2004 Q 2$ & 1 & -0.01 & 1 & 0 & 0 & 0 & 0 & -1.421 & -1.325 & 0.245 \\
\hline 2004Q3 & 1 & -0.01 & 1 & 0 & 0 & 0 & 0 & -1.365 & -1.149 & 0.234 \\
\hline 2004Q4 & 1 & -0.01 & 1 & 1 & 0 & 0 & 1 & -1.258 & -0.955 & 0.223 \\
\hline 2005Q1 & 1 & -0.29 & $\mathrm{Na}$ & $\mathrm{Na}$ & $\mathrm{Na}$ & 0.45 & 1 & $\mathrm{Na}$ & -0.760 & 0.186 \\
\hline $2005 Q 2$ & 1 & -0.29 & $\mathrm{Na}$ & $\mathrm{Na}$ & $\mathrm{Na}$ & 0.57 & 1 & $\mathrm{Na}$ & -0.557 & 0.159 \\
\hline $2005 Q 3$ & 1 & -0.29 & $\mathrm{Na}$ & $\mathrm{Na}$ & $\mathrm{Na}$ & 0.75 & 1 & $\mathrm{Na}$ & -0.340 & 0.131 \\
\hline $2005 Q 4$ & 1 & -0.29 & $\mathrm{Na}$ & $\mathrm{Na}$ & $\mathrm{Na}$ & 1.00 & 1 & $\mathrm{Na}$ & -0.100 & 0.103 \\
\hline 2006Q1 & 1 & -0.29 & 1 & 1 & 1 & 0.79 & 1 & -0.649 & 0.170 & 0.085 \\
\hline 2006Q2 & 1 & -0.29 & 1 & 1 & 1 & 0.70 & 1 & -0.425 & 0.474 & 0.073 \\
\hline $2006 Q 3$ & 1 & -0.29 & 1 & 1 & 1 & 0.65 & 1 & -0.173 & 0.803 & 0.058 \\
\hline 2006Q4 & 1 & -0.29 & 1 & 1 & 1 & 0.75 & 1 & 0.092 & 1.140 & 0.046 \\
\hline 2007Q1 & 1 & 0.11 & 1 & 1 & 1 & 0.63 & 1 & 0.347 & 1.453 & 0.058 \\
\hline 2007Q2 & 1 & 0.11 & 1 & 1 & 1 & 0.43 & 1 & 0.578 & 1.713 & 0.069 \\
\hline $2007 Q 3$ & 1 & 0.11 & 1 & 1 & 1 & 0.28 & 1 & 0.770 & 1.880 & 0.080 \\
\hline 2007Q4 & 1 & 0.11 & 1 & 1 & 1 & 0.17 & 1 & 0.910 & 1.920 & 0.092 \\
\hline 2008Q1 & 1 & -0.28 & 1 & 1 & 1 & 0.23 & 1 & 0.985 & 1.800 & 0.093 \\
\hline 2008Q2 & 1 & -0.28 & 1 & 1 & 1 & 0.24 & 1 & 0.990 & 1.505 & 0.093 \\
\hline 2008Q3 & 1 & -0.28 & 1 & 1 & 1 & 0.29 & 1 & 0.920 & 1.038 & 0.094 \\
\hline 2008Q4 & 1 & -0.28 & 1 & 1 & 1 & 0.38 & 1 & 0.787 & 0.435 & 0.096 \\
\hline 2009Q1 & 1 & -0.04 & 1 & 1 & 1 & 0.25 & 1 & 0.608 & -0.238 & 0.099 \\
\hline 2009Q2 & 1 & -0.04 & 1 & 1 & 1 & 0.08 & 1 & 0.434 & -0.845 & 0.102 \\
\hline 200903 & 1 & -0.04 & 1 & 1 & 1 & 0 & 1 & 0.294 & -1.291 & 0.105 \\
\hline $2009 Q 4$ & 1 & -0.04 & 1 & 1 & 1 & 0 & 1 & 0.189 & -1.541 & 0.108 \\
\hline $2010 Q 1$ & 1 & 0.05 & 1 & 1 & 1 & 0 & 1 & 0.105 & -1.590 & 0.112 \\
\hline 2010Q2 & 1 & 0.05 & 1 & 1 & 1 & 0 & 1 & 0.032 & -1.440 & 0.115 \\
\hline 2010Q3 & 1 & 0.05 & 1 & 1 & 1 & 0 & 1 & -0.065 & -1.167 & 0.117 \\
\hline
\end{tabular}

